\title{
Comparison of Clinical Characteristics and Outcome of Young and Older Patients with Oral Squamous Cell Carcinoma
}

\author{
Ichiro Ogura ${ }^{1,3}$, Teruo Amagasa ${ }^{1}$, Junichi Ishii ${ }^{1}$, Hiroshi Iwaki ${ }^{1}$, Tohru Kurabayashi ${ }^{2}$ and Takehito Sasaki ${ }^{2}$ \\ ${ }^{1}$ Maxillofacial Surgery, Graduate School, Tokyo Medical and Dental University, Tokyo, Japan \\ ${ }^{2}$ Oral and Maxillofacial Radiology, Graduate School, Tokyo Medical and Dental University, Tokyo, Japan \\ ${ }^{3}$ Department of Radiology, Nihon University School of Dentistry at Matsudo, Chiba, Japan
}

Ogura I, Amagasa T, Ishii J, Iwaki H, Kurabayashi T and Sasaki T. Comparison of clinical characteristics and outcome of young and older patients with oral squamous cell carcinoma. Oral Med Pathol 2003; 8: 21-26, ISSN 1342-0984.

\begin{abstract}
Oral squamous cell carcinoma (SCC) is relatively uncommon in patients less than 40 years of age. Of 411 patients with oral SCC treated, 27 patients $(6.6 \%)$ were less than 40 years of age. These cases of young age were compared with those of older age concerning their clinical characteristics and outcome. The five-year overall survival rate was $92.6 \%$ for young and $68.8 \%$ for older patients, respectively $(P=\mathbf{0 . 0 2 7})$. Using logistic multivariate regression analysis, including age, gender, primary site, TN category and treatment modality, only TN category and treatment modality were significant and independent predictive variables for recurrence, but age was not $(P<0.05)$. It was concluded that better prognosis observed in young patients with oral SCC was significantly determined by their characteristics of TN category and treatment modality, but not by their age.
\end{abstract}

Key words: oral cancer, squamous cell carcinoma, young patients, oral cavity

Correspondence: Teruo Amagasa, Maxillofacial Surgery, Graduate School, Tokyo Medical and Dental University, 1-5-45 Yushima, Bunkyo-ku, Tokyo 113-8549, Japan

Phone: +81-3-5803-5498, Fax: +81-3-5803-0198

\section{Introduction}

Oral squamous cell carcinoma (SCC) is relatively uncommon in patients less than 40 years of age. It has been estimated that less than $3 \%$ of all oral cavity SCCs occur in patients younger than 40 years of age (1-3). There have been a few reports regarding the outcome of patients younger than 40 years of age with oral tongue SCC (4-6). Some authors (4-5) reported that patients younger than 40 years old with SCC of the tongue had a higher rate of locoregional recurrence rate than did older patients. Other authors (6) have found young patients to have a prognosis similar to their older counterparts. However, these reports have been limited, mostly due to small numbers of patients, which has precluded meaningful statistical analysis and limited our understanding of etiology, natural history, and optimal therapeutic management, and outcome. Resolution of these issues is important because if age-related differences exist, treatment strategies for young patients may potentially be different. Our purpose, therefore, is to evaluate possible predictive variables for patients younger than 40 years of age with oral SCC by comparison with older patients.

\section{Patients and methods}

Patients

Four hundred eleven patients consisting of 270 males and 141 females with oral SCC treated at the First Department of Oral and Maxillofacial Surgery, Tokyo Medical and Dental University Hospital, from January 1988 to December 1997, were included in this study. The mean age of these patients was $59.6 \pm 13.1$ years (mean $\pm \mathrm{SD}$ ), with a range from 23 to 88 years (Fig. 1). Of these patients, 27 patients $(6.6 \%$; 20 males, 7 females $)$ were less than 40 years of age and were defined as young patients in this analysis. The mean age of the young patients was $31.7 \pm 4.9$ years, with a range from 23 to 39 years. The number of patients older than or equal to 40 years of age was 384 patients (250 males, 134 females) and the mean age was $61.6 \pm 11.1$ years, with a range from 40 to 88 years. All patients had a minimum 2-year follow-up.

Definitive diagnoses and histologic grading were rendered by biopsy. Histologic grading was classified into three types (Grade I, numerous epithelial pearls; Grade II, epithelial pearls infrequent or even absent; and Grade III, epithelial pearls rarely seen) according to the World 


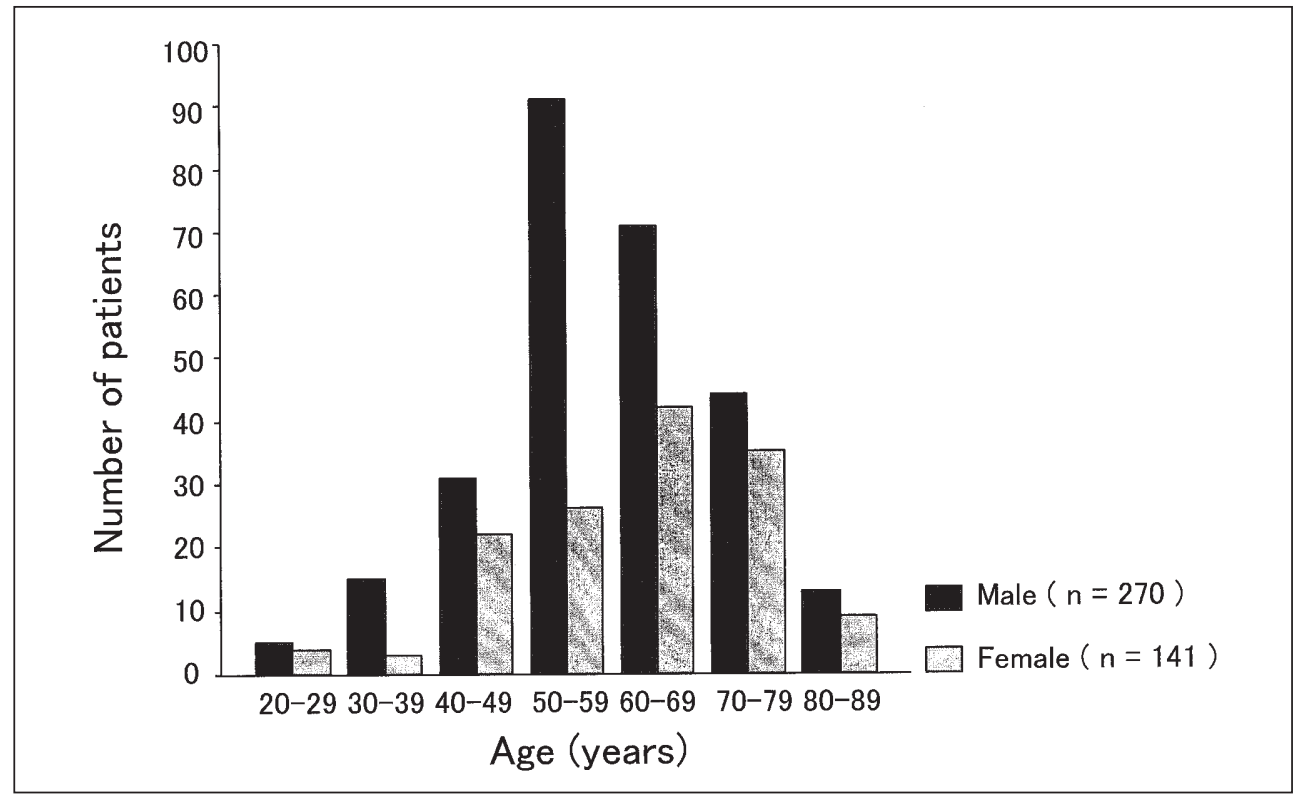

Fig. 1: Distribution of 411 patients of oral squamous cell carcinomas by age and gender Mean \pm standard deviation, $59.6 \pm 13.1$ years; range 23 to 88 years

Table 1: Summary of 27 cases of patients less than 40 years of age

\begin{tabular}{|c|c|c|c|c|c|c|}
\hline \multicolumn{2}{|c|}{$\begin{array}{l}\text { Age/Gender } \\
\text { Primary site }\end{array}$} & $\mathrm{UICC} / \mathrm{WHO}$ & Treatment & $\begin{array}{l}\text { Time/site } \\
\text { of recurrence }\end{array}$ & Salvage & $\begin{array}{l}\text { Outcome } \\
\text { (months) }\end{array}$ \\
\hline $23 / \mathrm{F}$ & tongue & T1N0M0 / Grade I & Partial glossectomy & None & & NED(31) \\
\hline $24 / \mathrm{M}$ & tongue & T1N0M0 / Grade I & Partial glossectomy & None & & NED(69) \\
\hline $25 / \mathrm{M}$ & tongue & T1N0M0 / Grade I & Partial glossectomy & None & & NED(24) \\
\hline $26 / \mathrm{F}$ & tongue & T1N0M0 / Grade I & Partial glossectomy & None & & NED(96) \\
\hline $29 / \mathrm{F}$ & tongue & T1N0M0 / Grade I & Partial glossectomy & None & & NED(28) \\
\hline $30 / \mathrm{M}$ & tongue & T1N0M0 / Grade I & Partial glossectomy & 5 months/neck & $\mathrm{RND}(\mathrm{pN} 2 \mathrm{~b})$ & $\operatorname{NED}(101)$ \\
\hline $30 / \mathrm{M}$ & tongue & T1N0M0 / Grade II & Partial glossectomy, $\mathrm{RND}(\mathrm{pN} 0)$ & None & & $\operatorname{NED}(36)$ \\
\hline $30 / \mathrm{M}$ & tongue & T1N0M0 / Grade II & Partial glossectomy & None & & $\mathrm{NED}(56)$ \\
\hline $31 / \mathrm{M}$ & tongue & T1N0M0 / Grade I & Partial glossectomy & None & & NED(57) \\
\hline $38 / \mathrm{M}$ & tongue & T1N0M0 / Grade II & Partial glossectomy & None & & $\mathrm{NED}(80)$ \\
\hline $26 / \mathrm{M}$ & tongue & T1N2bM0 / Grade II & Partial glossectomy, $\mathrm{RND}(\mathrm{pN} 2 \mathrm{~b})$ & None & & NED(44) \\
\hline $31 / \mathrm{M}$ & tongue & T2N0M0 / Grade II & $\begin{array}{l}\text { Preoperative XRT(30Gy), } \\
\text { Hemiglossectomy, } \\
\text { Reconstruction, RND(pN0) }\end{array}$ & 7 months/neck & None & $\operatorname{DOD}(12)$ \\
\hline $32 / \mathrm{M}$ & tongue & T2NOM0 / Grade I & Partial glossectomy & None & & $\operatorname{NED}(76)$ \\
\hline $33 / \mathrm{M}$ & tongue & T2N0M0 / Grade II & $\begin{array}{l}\text { Hemiglossectomy, } \\
\text { Reconstruction, RND(pN0) }\end{array}$ & None & & NED(39) \\
\hline $35 / \mathrm{F}$ & tongue & T2NOM0 / Grade I & Partial glossectomy & None & & $\mathrm{NED}(29)$ \\
\hline $37 / \mathrm{F}$ & tongue & T2N0M0 / Grade II & $\begin{array}{l}\text { Hemiglossectomy, } \\
\text { Reconstruction, RND(pN0) }\end{array}$ & None & & $\mathrm{NED}(53)$ \\
\hline $39 / \mathrm{F}$ & tongue & T2N0M0 / Grade II & Hemiglossectomy, RND(pN0) & None & & $\operatorname{NED}(122)$ \\
\hline $38 / \mathrm{M}$ & tongue & T2N1M0 / Grade I & Partial glossectomy, RND(pN1) & None & & $\mathrm{NED}(49)$ \\
\hline $34 / \mathrm{M}$ & tongue & T3N0M0 / Grade I & $\begin{array}{l}\text { Hemiglossectomy, } \\
\text { Reconstruction, RND(pN0) }\end{array}$ & None & & NED(33) \\
\hline $35 / \mathrm{M}$ & tongue & T3N0M0 / Grade II & $\begin{array}{l}\text { Hemiglossectomy, } \\
\text { Reconstruction, RND(pN0) }\end{array}$ & None & & $\operatorname{NED}(60)$ \\
\hline $29 / \mathrm{F}$ & tongue & T3N1M0/ Grade I & Hemiglossectomy, RND(pN1) & 15 months/lung & XRT & $\operatorname{DOD}(19)$ \\
\hline $27 / \mathrm{M}$ & tongue & T4N2cM0 / Grade II & $\begin{array}{l}\text { Preoperative XRT(20Gy), } \\
\text { Hemiglossectomy, } \\
\text { Reconstruction, RND(pN2c) }\end{array}$ & None & & $\mathrm{NED}(62)$ \\
\hline $35 / \mathrm{M}$ & lower gingiva & T1N0M0 / Grade II & Marginal resection & None & & $\mathrm{NED}(31)$ \\
\hline $39 / \mathrm{M}$ & lower gingiva & T1N0M0 / Grade II & Marginal resection & None & & $\operatorname{NED}(67)$ \\
\hline $27 / \mathrm{M}$ & lower gingiva & T4N0M0 / Grade I & $\begin{array}{l}\text { Segmental resection, } \\
\text { Reconstruction, } \mathrm{RND}(\mathrm{pN} 0)\end{array}$ & None & & NED(93) \\
\hline $34 / \mathrm{M}$ & upper gingiva & T1N0M0 / Grade I & Partial maxillectomy & None & & NED(32) \\
\hline $39 / \mathrm{M}$ & upper gingiva & T1N0M0 / Grade I & Partial maxillectomy & None & & $\mathrm{NED}(91)$ \\
\hline
\end{tabular}

UICC: TNM classification, WHO: Histologic grading, M: male, F: female, RND: radical neck dissection, XRT: radiotherapy, NED: no evidence of disease, DOD: dead of disease 
Health Organization (WHO) histologic grading system (7). TNM classification of the Union Internationale Contre le Cancer (UICC, 1997) was used to stage the disease(8). Clinical indication to therapeutic modalities was determined in our hospital by clinical conference of oral surgeons and radiation oncologists on an individual patient basis. In general, surgical resection alone for early stage and composite resection with reconstruction for advanced stage were performed, and radiotherapy alone was performed for the patients who had serious histories, such as cerebrovascular accidents, and who may not tolerate more aggressive surgical therapy.

\section{Statistical analysis}

Chi-square test with Fisher's exact test was used for the statistical significance. The statistical correlation between data was assessed by Spearman's rank correlation test. Overall survival time was determined as the time interval in months between initial treatment and death or until the date of follow-up. The overall survival rates were calculated with the Kaplan-Meier method. The log-rank test was used to test for the statistical signifi- cance of differences in overall survival curves.

The prognostic factors in recurrence (primary, regional and distant failure) were evaluated by logistic multivariate regression analysis. Variables included for the analysis were age, gender, primary site, TN category, and treatment modalities. $\mathrm{P}$ values $<0.05$ were considered statistically significant.

\section{Results}

Summary of 27 cases of patients less than 40 years of age is shown in Table 1. Distribution of primary site of the tumors is shown for both young and older patients in Table 2. The incidence of tongue carcinoma was significantly different between young $(81.5 \%)$ and older (56.8\%) patients $(\mathrm{P}=0.012)$. Male to female ratio was $2.9: 1$ in young and 1.9:1 in older patients $(\mathrm{P}=0.343)$. Table 3 showed patient distribution according to stage and TN category in young and older patients. The incidence of T1 of oral SCC was significantly different between young $(55.6 \%)$ and older $(32.5 \%)$ patients $(\mathrm{P}=0.015)$. The incidence of N0 of oral SCC was not significantly different between young $(85.2 \%)$ and older $(79.2 \%)$ patients $(\mathrm{P}=$

Table 2: Distribution of primary site of young and older patients

\begin{tabular}{|c|c|c|c|c|c|c|}
\hline \multirow[b]{2}{*}{ Site } & \multicolumn{3}{|c|}{ Young $(<40$ years old $)$} & \multicolumn{3}{|c|}{ Older $(\geq 40$ years old $)$} \\
\hline & M & $\mathrm{F}$ & Total & M & $\mathrm{F}$ & Total \\
\hline Tongue & 15 & 7 & $22(81.5)$ & 147 & 71 & $218 \quad(56.8)$ \\
\hline Lower gingiva & 3 & 0 & $3(11.1)$ & 37 & 24 & $61 \quad(15.9)$ \\
\hline Upper gingiva & 2 & 0 & $2 \quad(7.4)$ & 10 & 16 & $26 \quad(6.8)$ \\
\hline Buccal mucosa & 0 & 0 & $0 \quad(0.0)$ & 25 & 18 & $43 \quad(11.2)$ \\
\hline Floor of mouth & 0 & 0 & $(0.0)$ & 27 & 1 & $28 \quad(7.3)$ \\
\hline Hard palate & 0 & 0 & $\begin{array}{ll}0 & (0.0)\end{array}$ & 4 & 4 & (2.0) \\
\hline Total & 20 & 7 & $27(100.0)$ & 250 & 134 & $384(100.0)$ \\
\hline
\end{tabular}

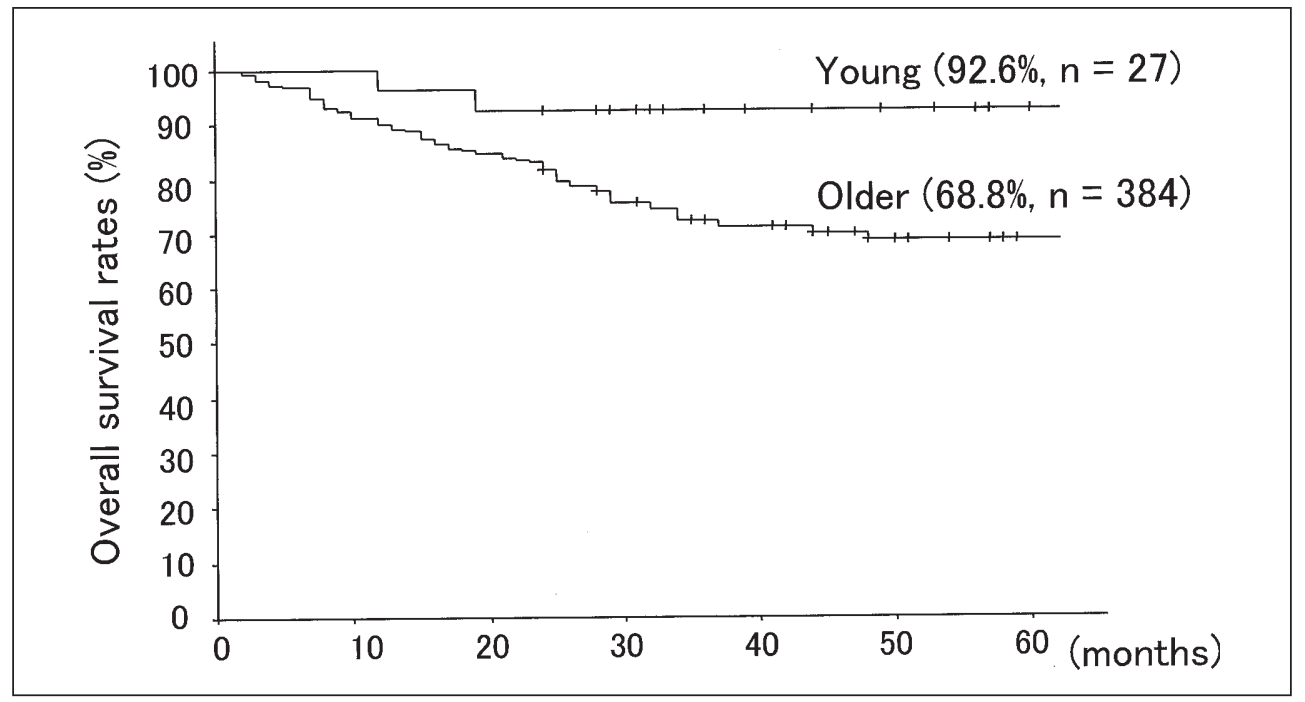

Fig. 2: Overall survival rates in young and older patients, $\mathrm{P}=0.027$ (Kaplan-Meier analysis) 
Table 3: Patient distribution according to stage, TN category

\begin{tabular}{|c|c|c|c|}
\hline & & $\begin{array}{c}\text { Young }(\%) \\
\mathrm{n}=27\end{array}$ & $\begin{array}{c}\text { Older }(\%) \\
n=384\end{array}$ \\
\hline \multirow[t]{4}{*}{ Stage } & I & $14(51.9)$ & $116(30.2)$ \\
\hline & II & $6(22.2)$ & $136(35.4)$ \\
\hline & III & $4(14.8)$ & $54(14.1)$ \\
\hline & IV & $3(11.1)$ & $78(20.3)$ \\
\hline \multirow[t]{4}{*}{$\mathrm{T}$ category } & $\mathrm{T} 1$ & $15(55.6)$ & 125 \\
\hline & $\mathrm{T} 2$ & 7 (25.9) & $178(46.4)$ \\
\hline & $\mathrm{T} 3$ & $3(11.1)$ & $43(11.2)$ \\
\hline & $\mathrm{T} 4$ & $2 \quad(7.4)$ & $38 \quad(9.9)$ \\
\hline \multirow[t]{5}{*}{$\mathrm{N}$ category } & No & $23(85.2)$ & $304(79.2)$ \\
\hline & N1 & $2 \quad(7.4)$ & $30 \quad(7.8)$ \\
\hline & $\mathrm{N} 2 \mathrm{a}$ & $\begin{array}{ll}0 & (0.0)\end{array}$ & $\begin{array}{ll}0 & (0.0)\end{array}$ \\
\hline & $\mathrm{N} 2 \mathrm{~b}$ & 1 & $37 \quad(9.6)$ \\
\hline & $\mathrm{N} 2 \mathrm{c}$ & $1 \quad(3.7)$ & $13 \quad(3.4)$ \\
\hline
\end{tabular}

0.454). The incidence of stage I of oral SCC was significantly different between young (51.9\%) and older (30.2\%) patients $(\mathrm{P}=0.019)$. The correlation between age and stage was not significant $(\mathrm{R}=0.087, \mathrm{P}=0.078$ ).

Table 4 showed patient distribution according to initial treatment modalities for primary tumor. In young patients, the composite surgical resection with reconstruction and the resection alone were performed in $13.6 \%$ and $86.4 \%$ for T1-T2 group, respectively. None of young patients received either radiotherapy alone or chemotherapy alone. On the other hand, in older patients, the composite resection with reconstruction and others (resection alone, brachytherapy alone, and external radiotherapy alone) were performed in $13.9 \%$ and $86.1 \%$ for T1-T2 group, respectively. The difference of treatment modality between young and older patients in T1-T2 group was not significant $(\mathrm{P}=0.999)$. The composite resection with reconstruction for T3-T4 group was performed for $80.0 \%$ in young and $44.4 \%$ in older patients, respectively ( $\mathrm{P}=$ $0.179)$.
Primary recurrence was found in none of the 27 young patients. Of 3 patients (11.1\%) with regional or distant recurrence, 2 died of disease. On the other hand, as for 384 older patients, 302 patients are alive with no evidence of disease, while 64 patients died of oral carcinoma (33 with primary failures, 19 regional failures, and 12 distant failures) and 18 patients died with other disease. The five-year overall survival rate was $92.6 \%$ for younger and $68.8 \%$ for older patients, respectively (Fig. $2, \mathrm{P}=0.027)$.

Logistic multivariate regression analysis demonstrated that $\mathrm{T}$ category $(\mathrm{P}=0.003$; odds ratio $=1.63)$ and $\mathrm{N}$ category $(\mathrm{P}<0.001$; odds ratio $=2.00)$ were significant and independent predictive variables for recurrence (Table 5). When the multivariate analysis was performed for young and older patients separately, again $\mathrm{T}$ category $(\mathrm{P}=0.003$; odds ratio $=1.62)$ and $\mathrm{N}$ category $(\mathrm{P}<0.001$; odds ratio $=2.03$ ) were significant and independent predictive variables for recurrence in older patients. On the other hand, there was no significant predictive variable for recurrence in younger patients.

Furthermore, when the multivariate analysis was performed by excluding $\mathrm{N}$ category, $\mathrm{T}$ category $(\mathrm{P}=0.001$; odds ratio $=1.71)$ and treatment modality $(\mathrm{P}=0.048$; odds ratio $=1.90$ ) had significant and independent predictive variables for recurrence (Table 6 ). When the multivariate analysis was performed for young and older patients separately, again $\mathrm{T}$ category $(\mathrm{P}=0.001$; odds ratio $=1.69)$ and treatment modality $(\mathrm{P}=0.045$; odds ratio $=1.93)$ were significant and independent predictive variables for recurrence in older patients. On the other hand, nothing was a significant predictive variable for recurrence in younger patients.

The correlations between $\mathrm{T}$ category and $\mathrm{N}$ category, between $\mathrm{T}$ category and treatment modality, and between $\mathrm{N}$ category and treatment modality of young and older patients with oral SCC were significant $(\mathrm{R}=0.268$; $\mathrm{P}<$ $0.001, \mathrm{R}=-0.374 ; \mathrm{P}<0.001, \mathrm{R}=-0.394 ; \mathrm{P}<0.001$, respectively).

\section{Discussion}

It has been reported that the percentage of SCC of the oral cavity and oropharynx in patients under 40 years of age ranges from $0.9 \%$ to $2.7 \%$ of oral SCC of all ages (1-

Table 4: Patient distribution according to treatment modalities and T category

\begin{tabular}{|c|c|c|c|c|}
\hline \multirow{2}{*}{$\begin{array}{l}\text { Initial treatment of } \\
\text { primary tumor }\end{array}$} & \multicolumn{2}{|c|}{ Young (\%) } & \multicolumn{2}{|c|}{ Older $(\%)$} \\
\hline & $\mathrm{T} 1-\mathrm{T} 2 \quad(\%)$ & $\mathrm{T} 3-\mathrm{T} 4 \quad(\%)$ & $\mathrm{T} 1-\mathrm{T} 2(\%)$ & T3-T4 (\%) \\
\hline Resection with reconstruction & $3 \quad(13.6)$ & $4 \quad(80.0)$ & $42 \quad(13.9)$ & $36 \quad(44.4)$ \\
\hline Resection alone & $(86.4)$ & $1 \quad(20.0)$ & $197 \quad(65.0)$ & $27 \quad(33.3)$ \\
\hline Brachytherapy alone & $(0.0)$ & $(0.0)$ & $53 \quad(17.5)$ & $(6.2)$ \\
\hline External radiotherapy alone & $(0.0)$ & $(0.0)$ & $(3.6)$ & $13 \quad(16.1)$ \\
\hline Total & $22(100.0)$ & $5(100.0)$ & $303(100.0)$ & $81(100.0)$ \\
\hline
\end{tabular}


Table 5: Prognostic factors in oral SCC by logistic multivariate regression analysis

\begin{tabular}{lrrr}
\hline & Odds ratio & $95 \%$ CI & P value \\
\hline Age (years): <40 vs. 40 & 0.46 & $0.12-2.17$ & .328 \\
Gender: male vs. female & 0.79 & $0.44-1.42$ & .433 \\
Primary site: tongue vs. others & 1.02 & $0.57-1.85$ & .938 \\
T categories: T1-T4 & 1.63 & $1.19-2.24$ & .003 \\
N categories: N0-N2 & 2.00 & $1.40-2.86$ & $<.001$ \\
Treatment modality: resection with reconstruction vs. others & 1.21 & $0.60-2.42$ & .595 \\
\hline 95\% CI: 95\% confidence interval & & &
\end{tabular}

Table 6: Prognostic factors in oral SCC by logistic multivariate regression analysis excluding N category

\begin{tabular}{lrrr}
\hline & Odds ratio & 95\%CI & P value \\
\hline Age (years): <40 vs. 40 & 0.41 & $0.09-1.88$ & .252 \\
Gender: male vs. female & 0.75 & $0.43-1.33$ & .332 \\
Primary site: tongue vs. others & 0.97 & $0.54-1.73$ & .919 \\
T categories: T1-T4 & 1.71 & $1.25-2.32$ & .001 \\
Treatment modality: resection with reconstruction vs. others & 1.90 & $1.01-3.58$ & .048 \\
\hline
\end{tabular}

95\% CI: $95 \%$ confidence interval

3). The incidence of oral SCC in patients younger than 40 years old is $6.6 \%$ in our present study, which is somewhat higher than the reported rate. As for site distribution, our result indicates that the incidence of tongue carcinoma is significantly different between young $(81.5 \%)$ and older (56.8\%) patients. Although the roles of smoking and drinking alcohol in the aetiology of oral cancer are common knowledge among the medical community (9-10), it seems that there is a strong association with population-specific aetiological agents, particularly chronic stimulus by teeth, regarding tongue carcinoma in young patients. We report also that the incidence of T1 of oral SCC is significantly different between young $(55.6 \%)$ and older (32.5\%) patients. It is considered that early detection and medical examination are possible because young patients may have better oral health care than older patients.

An aggressive therapeutic approach to young patients with oral SCC appears warranted in an attempt to improve to ultimate survival (1-2,4). Son et al. (1) showed that oral cavity and oropharyngeal cancer in young adults carried a dismal prognosis with a 3-year actuarial survival of $17 \%$ and locoregional failure rate of $91 \%$. Cusumano et al. (2) showed that all five patients with stage I and II of oral cavity carcinoma as young adults survived 5 years, compared with only one of six patients with stage III and IV disease. Sarkaria et al. (4) showed that five of six patients with tongue cancer as young adults had developed locoregional failure and four patients had died from their cancer.

The present study showed that the composite re- section with reconstruction for T3-T4 cases was performed for $80.0 \%$ in young and $44.4 \%$ in older patients, respectively. This is because young patients could tolerate aggressive operations whereas some older patients with serious histories, such as cerebrovascular accidents, may have not received more aggressive surgical therapy.

The prognostic factors of young patients with SCC of the oral cavity and oropharynx are still controversial (1-6). Although age has been reported as a significant factor, some authors (4-5) reported that patients younger than 40 years old with SCC of the tongue had a higher rate of locoregional recurrence rate than did older patients. Other authors (6) have found young patients to have a prognosis similar to their older counterparts. This study indicated that the five-years overall survival rates of young and older were $92.6 \%$ and $68.8 \%$, respectively. Further, this study demonstrated that using logistic multivariate regression analysis with including age, gender, primary site, TN category and treatment modality, only TN category and treatment modality were significant and independent prognostic factors, but the age was not.

Although the prognosis of young patients with oral SCC was better than the older patients in this study, this is strongly suggested because young patients could be performed more aggressive therapy for advance stage. It was concluded that the prognostic factors of young patients with oral SCC were TN category and treatment modality, rather than the age. This suggests that improvement of therapeutic outcome may be possible for older patient by careful selection of the treatment modality. Further analysis for this hypothesis should be continued. 


\section{References}

1. Son YH and Kapp DS. Oral cavity and oropharyngeal cancer in a younger population. Cancer 1985; 55: 441-4.

2. Cusumano RJ and Persky MS. Squamous cell carcinoma of the oral cavity and oropharynx in young adults. Head Neck Surg 1988; 10: 229-34.

3. Burzynski NJ, Flynn MB, Faller NM, et al. Squamous cell carcinoma of the upper aerodigestive tract in patients 40 years of age and younger. Oral Surg Oral Med Oral Pathol 1992; 74: 404-8.

4. Sarkaria JN and Harari PM. Oral tongue cancer in young adults less than 40 years of age: rationale for aggressive therapy. Head Neck 1994; 16: 107-11.

5. Friedlander PL, Schantz SP, Shaha AR, et al. Squamous cell carcinoma of the tongue in young patients: a matched-pair analysis. Head Neck 1998; 20: 363-8.

6. Pitman KT, Johnson JT, Wagner RL, et al. Cancer of the tongue in patients less than forty. Head Neck 2000; 22: 297302.

7. WHO. Histological typing of oral and oropharyngeal tumours. WHO. Geneva. 1971; 15-9.

8. International Union Against Cancer. TNM classification of malignant tumours (ed 5). Wiley-Liss. New York. 1997; 1-50.

9. Prince S and Bailey BMW. Squamous carcinoma of the tongue: review. Br J Oral Maxillofac Surg 1999; 37: 164-74.

10. Kerawala CJ. Oral cancer, smoking and alcohol: the patients' perspective. Br J Oral Maxillofac Surg 1999; 37: 374-6.

(Accepted for publication September 20, 2002) 